\title{
New Technologies Aid Understanding of the Factors Affecting Adélie Penguin Foraging
}

\author{
By Walker O. Smith Jr., David G. Ainley, Karen J. Heywood, and Grant Ballard
}

The Ross Sea (Figure 1) is home to 33\% of the world's Adélie penguins (Pygoscelis adeliae), as well as substantial numbers of Emperor penguins (Aptenodytes forsteri), Weddell seals (Leptonychotes weddellii), and pelagic birds (Smith et al., 2014). Among these, the Commission for the Conservation of Antarctic Marine Resources (CCAMLR) has designated the Adélie penguin an "indicator species" for monitoring ecosystem structure and function in the newly designated Ross Sea Region Marine Protected Area (RSR-MPA). This penguin, among the best-known seabirds, has been studied for decades at multiple locations with investigations that have delved into its population history (both recent and through thousands of years), survival strategies, responses to environmental changes, and feeding ecology (summarized in Ainley, 2002, with numerous papers published thereafter).

Penguin populations are increasing in the southern Ross Sea, potentially indicating a broad response to an environment being altered by climate change and increased fishing activity. Despite extensive research, our understanding of the species' response to its changing habitat and food web is incomplete. Sea ice in the Ross Sea region has been increasing, at least until recent years, and this would be expected to affect populations of species that depend on the ice for predator avoidance and availability of

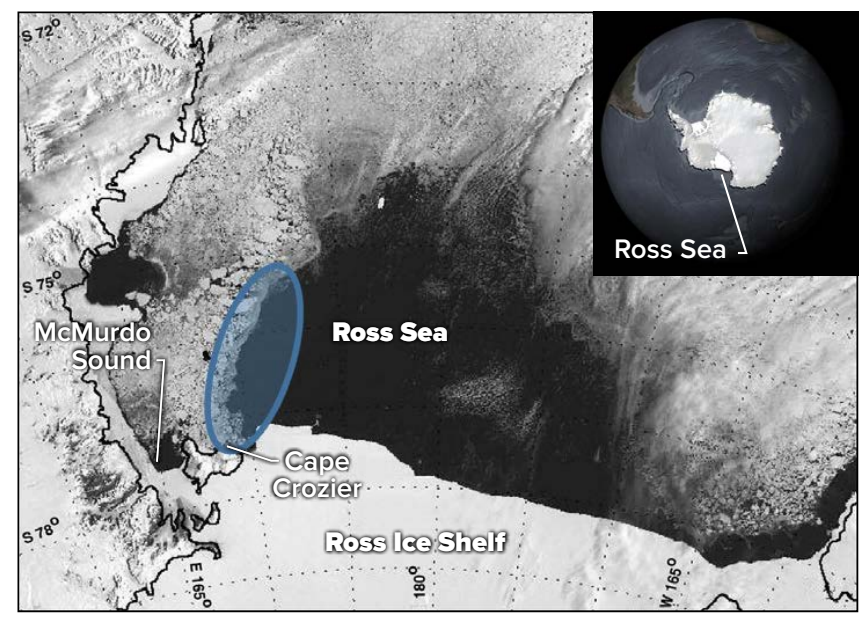

FIGURE 1. Location of foraging area (blue oval) of the Cape Crozier, Ross Sea, Adélie penguin colony superimposed on a typical late spring ice distribution map. Maximum foraging distance is $\sim 120 \mathrm{~km}$ from Cape Crozier. Inset shows the location of the Ross Sea adjacent to the southern Pacific. Ice map from NASA, November 1998 prey (crystal krill Euphausia crystallorophias and silverfish Pleuragramma antarctica, both associated with ice; Ainley, 2002). In addition, industrial fishing for Antarctic toothfish, a competitor for the same prey, has been practiced since 1997, potentially increasing prey abundance and reducing competition. Understanding the effects of these and other habitat changes on the penguin, its competitors, and prey requires further investigation.

The RSR-MPA was established in 2017 with the major goal "to conserve natural ecological structure, dynamics, and function throughout the Ross Sea region at all levels of biological organization by protecting habitats that are important to native mammals, birds, fishes, and invertebrates." Given that southern Ross Sea penguins live mostly within the RSR-MPA during their life cycles, ecological interactions near their nesting grounds are important to the entire MPA, and understanding the role of penguins within the continental shelf food web and biogeochemical cycles will directly facilitate achievement of RSR-MPA goals.

Ongoing advances in the use of bio-loggers on animals that are near the top of the food web have provided insights into these animals' ecology. Various devices that can be attached to penguins to quantify predatory behavior in time and space include simple sensors that record the conductivity (salinity) and temperature of seawater; fluorometers; "crittercams" (cameras mounted on an animal to monitor diving and feeding behavior); time-depth recorders; satellite tracking tags; and accelerometers (measuring head movements, which are an indication of active feeding; Figure 2). The devices have become small enough that they have no effect on penguin behavior. Using ocean gliders in the Ross Sea (Figure 3), especially those that carry active acoustic devices for monitoring the distribution of Adélie penguin prey in the water column, has also allowed an assessment of temporal and spatial changes in prey abundance during spring and summer, as well as their changes relative to the abundance of phytoplankton (microscopic marine algae) and water column structure (Ainley et al., 2015). Advanced molecular tools (stable isotopes, DNA analyses) permit the diets of penguins to be more easily quantified. Satellite imagery and passively recording sounds in the sea have allowed determination of the distribution of competing species (whales, seals) and their overlap with penguin foraging areas. 


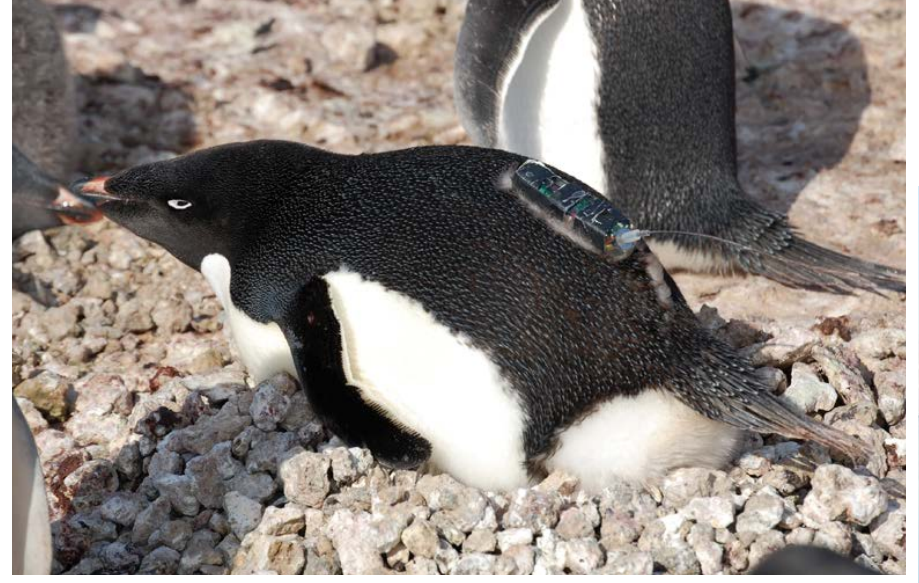

FIGURE 2. An Adélie penguin with an attached bio-logger. The sensors are attached using Tesa tape and are easily removed when penguins return to land. Previous investigations have shown that such bio-loggers do not impede penguin foraging or survival. Photo credit: Jean Pennycook

Penguins occupying large colonies like Cape Crozier (which has over 120,000 breeding pairs) must travel further to find food in late summer because prey availability closer to the colony has been severely depleted by penguin, seal, and whale feeding. In addition, because feeding frequency and food quality are very important to chick growth and survival, nutrition demands of their chicks increase as the ice-free season progresses (Ainley et al., 2015). Numerous additional factors affect post-fledging chick survival (predation, episodic weather events), and the effects of ecological interactions within the "preyscape" and of oceanographic conditions await further investigation. Beyond the area of intense predator foraging, vertical distributions and school/swarm structures of fish and krill may be significantly different (e.g., larger, more cohesive, and shallower) from those within. These prey patches would thus be "reservoirs" available once penguins leave their central foraging area. Predation- and predator-induced changes in prey distributions could be further assessed by quantifying prey habitat quality and by determining the effects of oceanographic habitat attributes, such as water column characteristics and phytoplankton concentrations, on prey distributions in areas of higher predation.

To better understand and monitor the food web dynamics and structure of a Southern Ocean trophic hotspot, and to resolve the penguin population growth paradox, a combination of technologies and approaches is needed, including:

1. Deployment of a suite of gliders with acoustic devices in a tight grid to measure the composition and assess the size, location, and density of prey, both inside and outside of intense penguin foraging areas

2. Deployment of gliders and miniature loggers attached to penguins to quantify oceanographic patterns (such as vertical ocean characteristics, irradiance, and particulate matter concentrations) in the ocean preyscape

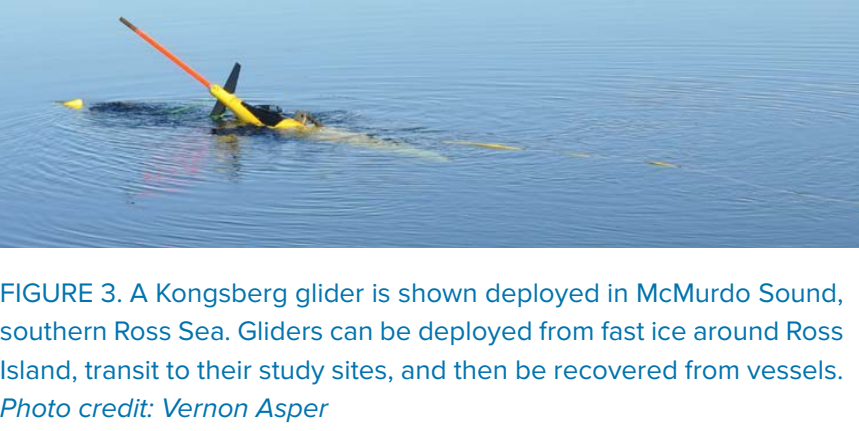

3. Use of penguin bio-logging to quantify foraging areas and their seasonal changes as well as overlap with competing species

4. Direct and DNA stable isotope analyses of penguin diet

5. Quantification of abundance and distribution of competing whales and seals using satellite imagery

New technologies have revolutionized our understanding of numerous aspects of the ocean. By merging these techniques with new hypotheses about basic ecological processes operating in the ocean, a far greater understanding of factors controlling mesopredator activities and distributions can be attained in harsh environments such as the Ross Sea. This enhanced knowledge will ultimately lead to the conservation and preservation of The Last Ocean (title of award-winning documentary film by Peter Young) and enable a new generation of marine scientists to unravel remaining unknowns.

\section{REFERENCES}

Ainley, D.G. 2002. The Adélie Penguin: Bellwether of Climate Change. Columbia University Press, NY, 416 pp.

Ainley, D.G., G. Ballard, R.M. Jones, D. Jongsomjit, S.D. Pierce, W.O. Smith Jr., and S. Veloz. 2015. Trophic cascades in the western Ross Sea, Antarctica: Revisited. Marine Ecology Progress Series 534:1-16, https://doi.org/10.3354/meps11394.

Smith, W.O. Jr., D.G. Ainley, K.R. Arrigo, and M.S. Dinniman. 2014. The oceanography and ecology of the Ross Sea. Annual Review of Marine Science 6:469-487, https://doi.org/10.1146/ annurev-marine-010213-135114.

ARTICLE DOI: https://doi.org/10.5670/oceanog.2021.supplement.02-10 


\section{AUTHORS}

Walker O. Smith Jr. (wos@vims.edu), Virginia Institute of Marine Science, College of William \& Mary, USA, and School of Oceanography, Shanghai Jiao Tong University, Shanghai, PRC. David G. Ainley, H.T. Harvey \& Associates Ecological Consultants, USA. Karen J. Heywood, Centre for Ocean and Atmospheric Sciences, School of Environmental Sciences, University of East Anglia, UK. Grant Ballard, Point Blue Conservation Science, USA.

\section{ARTICLE CITATION}

Smith, W.O. Jr., D.G. Ainley, K.J. Heywood, and G. Ballard. 2021. New technologies aid understanding of the factors affecting Adélie penguin foraging. Pp. 26-27 in

Frontiers in Ocean Observing: Documenting Ecosystems, Understanding Environmental Changes, Forecasting Hazards. E.S. Kappel, S.K. Juniper, S. Seeyave, E. Smith, and M. Visbeck, eds, A Supplement to Oceanography 34(4), https://doi.org/10.5670/ oceanog.2021.supplement.02-10.

\section{COPYRIGHT \& USAGE}

This is an open access article made available under the terms of the Creative Commons Attribution 4.0 International License (https://creativecommons.org/ licenses/by/4.0/), which permits use, sharing, adaptation, distribution, and reproduction in any medium or format as long as users cite the materials appropriately, provide a link to the Creative Commons license, and indicate the changes that were made to the original content. 